\title{
A review of spontaneous combustibility of oxidized coal
}

\author{
Kai Wang1, a , Xiaowei Zhai', b, Shangrong Jiang ${ }^{3, c}$ and Hui Ge ${ }^{\text {4,d }}$ \\ ${ }^{1}$ X'an University of Science and Technology, Xi'an, China \\ ${ }^{2}$ Xi'an University of Science and Technology, Xi'an, China \\ ${ }^{3}$ Xi'an University of Science and Technology, Xi'an, China \\ ${ }^{4}$ Xi'an University of Science and Technology, Xi'an, China \\ awangk912@xust.edu.cn, bzhaixw@xust.edu.cn, c13649236480@163.com, d951162092@qq.com
}

Keywords: Oxidized coal; Coal spontaneous combustion; Microstructure characteristics; Oxidation kinetics; Structure-function relationship

Abstract. Oxidized coal is the coal that recovered to environment temperature when the heat-storing environment is destroyed during the self-heating process, which is quite common in the process of coal mining and utilization. The spontaneous combustibility of oxidized coal differs from that of raw coal, which needs to be studied specially. In this paper, the development of microstructure characteristics, spontaneous combustibility and structure-function relationship of oxidized coal was reviewed. The proposed shortcomings, less of influence effects and factors, had been summarized. On the basis of deficiencies, the suggestions of studying microstructure mechanism and gross feature of coal secondary oxidation, also the structure-function relationship were put forward.

\section{Introduction}

All Coal spontaneous combustion hazard threatens the coal mining and utilization. Due to the self-heating property, once revealed and contacted with oxygen, coal would be oxidized. If the conditions outside destroyed the heat storage environment in this process, coal would be cooled down, then oxidized coal is formed. It is quite common in the process of coal mining and using, such as residual coal in upper goaf of layering mining of close distance coal seam groups and thick coal seam, coal in recovery working face, coal in the closed fire area which is extinguished [1]. In addition, outcrop or ground coal storage pile, due to the comprehensive effect of natural environment of the wind, sun or rain, could become oxidized coal, also called weathering coal. Due to the initial oxidation, the microstructure of coal changes in different degrees, which lead to different spontaneous combustibility, showing the enhancement or weakening effect.

The mining practice shows that oxidized coal is usually more easily spontaneous combustion than the raw coal. For example, there was a special gas explosion accident in Babao coal mine in 2013. The main reason was that the air leakage from upper section of working face, leading to the oxidation of coal, which caused gas explosion in Goaf [2]. Also, the residual coal in the re-mining area of the working face is very easy to self-heat [3], and the sealing of the closed fire area is very easy to reignite [4], which indicates the self-heating enhancement effect of oxidized coal. However, in the natural oxidation conditions, the weathering coal is not prone to spontaneous combustion, showing the weakening characteristic of spontaneous combustion. In recent years, the spontaneous combustibility of oxidized coal was more and more accounted, including the mechanism and kinetics characteristic parameters. Organization of the Text

\section{Microstructure characteristics of oxidized coal}

The combustion of coal is an extremely complex physical chemical process, which is closely related to its microstructure with the dynamic change of physical and chemical properties. A large number of studies have shown that the spontaneous combustion of coal is closely related to the structure. At present, XRD, XPS, infrared spectroscopy and other experimental methods are used to study the microstructure characteristics of coal oxidation. 
Mahidin[5] used the industrial analysis experiment to compare the samples of raw coal and oxidized coal, and found that with the increase of pre-oxidation temperature, the water and volatilization of the oxidized coal decreased rapidly and the oxidization increased rapidly. By the XRD experiment method, Dai [6] tested the microcrystalline structure characteristics of coal at different temperatures, and found the gradually decreasing of layer spacing and increasing of average diameter of the aromatic layer with the increasing of oxidation temperature. Li [7] used XPS technology to find that main existence form of carbon on the surface of raw coal was carbon-carbon bonds or carbon hydrogen bonds. After the carbon elements of the coal were gradually oxidized, the content of carbon and oxygen slightly increased, and the carboxyl group increased obviously. Using infrared spectrum analysis method, Chu [8] analyzed microstructure and characteristics of oxidized coal samples under different temperatures, and got the functional group distribution, which considered that the hydroxyl group in coal molecule and the methylene group connected with aromatic group were more active groups.

Infrared spectrum technology was used to study the coal samples at different temperature by Zhou [9]. Through differential spectral analysis, the change law of each group in the process of coal oxidation heating up was obtained, and the coal oxygen compound reaction activity of the groups was obtained: amino > methyl, aromatic methylene > carboxylic acids, lipids, vinyl > ethers. Kong [10] compared the infrared spectrum of coal samples before and after oxidation. The lower metamorphic coal contains more active groups such as phenolic hydroxyl group, alcohol hydroxyl group and so on. After oxidation, the aliphatic chain was broken, alcohols and phenols were oxidized to carboxylic acids, and aromatic rings were not affected for their high stability. By the method of infrared spectrum experiment, Deng [11] compared the characteristic parameters of oxidized and raw coal samples in Shaanxi Jurassic coal field, and found decreasing of moisture, increasing of oxygen content and surface area, and the number of aromatic hydrocarbon structure and fat structure were decreased for the oxidized coal. By infrared spectroscopy, Xia [12] tested the oxidation of coal surface oxygen functional groups $(\mathrm{C}-\mathrm{O}, \mathrm{C}=\mathrm{O}, \mathrm{COOH})$ and the serious weathering coal surface oxidation. In addition, using quantum chemical simulation, Wang [13] found that the structure model of coal was constructed, simulating the adsorption and oxidation reaction mechanism of coal at different temperatures.

\section{Dynamic characteristics of spontaneous combustion of oxidized coal}

The Due to the microstructure changes of oxidized coal, the re-oxidation process shows different spontaneous combustion characteristics. The dynamic characteristics of the spontaneous combustion process of oxidized coal are studied by using different heating methods.

$\mathrm{Ma}[14]$ tested the quality and its change rate of the lignite in the oxidation process under different temperatures, and found that the characteristic temperatures of coal spontaneous combustion. Moreover, coal could be oxidized to be higher than the environment temperature. Li [15] tested the influence of temperature on the law of gaseous compound emission during the coal spontaneous combustion process with the method of programmed heating. Qi [16] tested the dynamics characteristics of oxidized coal samples under different oxygen concentration in the lean oxygen environment during the coal spontaneous combustion process. The lower the oxygen concentration was, the higher the activation energy needed. And the activation energy in low temperature stage was higher than that in high temperature stage. Yuan [17] found that after initial oxidation, the coal activity in secondary oxidation process increased, in response to activation energy was reduced. When the oxidation temperature is higher, the energy needed for secondary oxidation reaction was lower. Chen [18] applied thermogravimetric analysis technique to study the combustion reaction activation energy of oxidized coal with different oxidation degree by the Coats-Redfern integral method. Compared with raw coal sample, high temperature treatment of coal sample resulted in higher oxidation activity. 
Some scholars have studied the spontaneous combustion characteristic parameters of oxidized coal. Wen [19] found that $\mathrm{CO}$ production rate and oxygen consumption rate increased with the increasing temperature in the process of coal spontaneous combustion. Zhang [20] studied the spontaneous combustion characteristics of raw coal and oxidized coal, using temperature programmed experiment, finding that the spontaneous combustion risk of oxidized coal enhanced. Yang [21] developed the fire area sealing and rekindling simulation experiment system independently, and studied the rule of gas products of coal in the fire areas under different conditions. With infrared spectrum, Lu [22] studied the problem of unsealing coal, and found that the physical and chemical condition changes in the heating process of coal in goaf, oxygen adsorbing is easy for heat transfer, and prone to spontaneous combustion. Zhang [23] analyzed the relationships between the concentration of $\mathrm{CO}$ and $\mathrm{CO}_{2}$ and time for oxidized coal samples and raw coal sample, considered that the gas concentration of coal samples was reducing with the increasing of time, and the gas concentration of oxidized coal samples was lower than that of raw coal sample. In addition, Deng [24] carried out the inhibition experiment with selected the different resistance agents for the oxidized coal, determining the inhibitor agent working and promoting burning time.

\section{Relationship between microstructure and spontaneous combustion of oxidized coal}

On the basis of essential relationship between coal spontaneous combustion macroscopic characteristics and its microstructure change rule, some scholars used different methods and technologies to establish the relationships between microscopic structure and spontaneous combustion characteristic parameters, and tried to reveal the spontaneous combustion mechanism of oxidized coal from different angles.

Dong [25] attained micro pore distribution data of different coal sample using the mercury injection experiment, and tested the relationships between microscopic pore structure of coal and spontaneous combustion tendency under different temperatures through the simulation of coal spontaneous combustion experiment system. DV Miroshnichenko [26] carried out pre-oxidation on the coal sample by heating, and studied the influences of oxidation activity on the functional groups types on coal surface and the number change using TPD-MS and TG-DTA, which found that the surface functional groups and distribution of different oxidation degree of coal samples were different. $\mathrm{Yu}$ [27] tested oxidized coal samples under different temperature with infrared spectrum experiment. The results showed that the reaction of various functional groups of coal in the activation need different energy, types and number of functional groups in the oxidation reaction. Through analysis of the absorbance for oxidized coal and fresh sample of wuda mining area with infrared spectral analysis technology, Xu [28] revealed the characteristics functional groups change law of coal before and after oxidation.

Guo [29] compared and studied the coal oxidation process of raw coal and oxidized coal, and found that the burning temperature of oxidized coal declined. When the temperature of bituminous coal increased with the evaporation of water, the fat hydrocarbon chain of coal broke, and alcohol, phenol was oxidized to carboxylic acid. Aromatic ring and ether bond were not affected due to its high stabilities. Liu [30] tested the structure characteristics of lignite under different temperatures with infrared spectrum analysis and EDS, identifying the impact of pre-oxidation temperature on lignite spontaneous combustion based on the junction temperature. It found that the content of oxygen element and the number of oxidation active group on coal surface were added by oxidation, demonstrating that the existences of aliphatic chains, functional groups containing oxygen, new free radicals and the increasing of specific surface area. The different oxidation temperatures had different influences on the spontaneous combustion characteristics of oxidized coal. Zhao [31] found there was crossing temperature in oxygen consumption rate and exothermic strength curves between the raw coal and oxidized coal, and oxidized coal in low temperature stage showed stronger abilities of oxygen consumption, through different metamorphic degree of oxidized coal with infrared spectrum and temperature programmed experiment. 


\section{Conclusions}

So far, the influence factors and mechanism of enhancement or weaken effect for oxidized coal have not been clearly defined and become an important scientific problem to be solved urgently. There are the following shortcomings for spontaneous combustion of oxidized coal:

1) Microstructure characteristics of oxidized coal change in different degrees due to initial oxidation conditions have not been demonstrated;

2) The study on main influence factors of the pre-oxidation temperature and oxygen concentration on oxidation dynamic characteristics of oxidized coal which are different from that in the initial oxidation is less.

Therefore, experimental, theorical and mathematical method should be used to study microstructure features of oxidized coal, determine the influences factors of the degree of oxidation and establish the structure-function relationships between microstructure features and the characteristic of spontaneous combustion of oxidized coal, which have the critical scientific significances on safety mining in the closed distance coal seam group, layering in thick coal seam and re-mining working face.

\section{Acknowledgements}

This work was supported by the National Natural Science Foundation of China (No.51404195, 51704226), the China Postdoctoral Science Foundation (No. 2016M592819), Natural Science Basic Research Plan in Shaanxi Province of China (Program No. 2017JQ5047), and Scientific Research Program Funded by Shaanxi Provincial Education Department (No. 17JK0500).

\section{References}

[1] D. Han, J. Sun: Coal Geology of China, Vol.10(1998), p.15-16 In Chinese

[2] Information on http://www.chinasafety.gov.cn

[3] J. Deng, W. Ma, X. Zhang: Coal Science and Technology, Vol.38( 2010), p.43 In Chinese

[4] Y. Bao: Coal Science and Technology, Vol.41(2013), p.70 In Chinese

[5] Mahidin, Hiromoto Usui, and Singo Ishikawa Hamdani: Coal Preparation, Vol.22(2002), p.81

[6] G. Dai: Journal of China Coal Society, Vol.36(2011), p.322 In Chinese

[7] L. Zhang, Z. Li, J. Li, et al: Coal Technology, Vol.35(2016), p.226 In Chinese

[8] T. Chu, S., Y. Sun, et al: China Safety Science Journal, Vol.18(2008), p.171 In Chinese

[9] P. Zhou: Coal Conversion, Vol.37(2014), p.15 In Chinese

[10] L. Kong, in: Effect of Low Temperature Oxidation on The Structures and Properties of Coal. Beijing University of Chemical Technology, (2014) In Chinese

[11] J. Deng, J. Zhao, Y. Zhang, et al: China Safety Science Journal, Vol.24(2014), p.1 In Chinese

[12] W. Xia. in:Difficult-to-float Mechanism and Floatability Improvement of Taixi Oxidized Coal, China University of Mining and Technology,(2014) In Chinese

[13] J. Wang, C. Deng: Journal of China Coal Society, Vol.32(2007), p.1291 In Chinese

[14] H. Ma: Morden Mining, Vol.25(2009), p.43 In Chinese

[15] J. Li, D. Wang, X. Zhong, et al: China Safety Science Journal, Vol.21(2011), p.72 In Chinese

[16] G. Qi, D. Wang, K. Zheng, et al: Journal of Loss Prevention in the Process Industries, Vol.35 (2015), p. 224 In Chinese 
[17] Y. Tao, in: Experimental Study of Spontaneous CombustionCharacteristics of Oxidized 1/3 Coking Coal, AnHui University of Science and Technology, (2004) In Chinese

[18] K. Chen, R. Qin: Coal and Chemical Industry, Vol.37(2014), p.23 In Chinese

[19] H. Wen, H. Jiang, X. Zhai, et al: Safety in Coal Mines, Vol.44(2013), p.38 In Chinese

[20] X. Zhang, Q. Li:Coal Science and Technology, Vol.42(2014), p.37 In Chinese

[21] X. Yang, N. Li: Safety in Coal Mines, Vol.41(2010), p.4 In Chinese

[22] W. Lu, J. Li, X. Yang: Safety in Coal Mines, Vol.44(2013), p.233 In Chinese

[23] Y. Zhang, J. Wu, L. Chang, et al: Journal of Loss Prevention in the Process Industries, Vol.26 (2013), p.1221 In Chinese

[24] Jun Deng, Shao-wu Ai, Li Ma, et al: Coal Science and Technology, Vol.43(2015), p.59 In Chinese

[25] X. Dong, F. Wang, Y. Meng, et al:Coal Science and Technology, Vol.42(2014), p.41 In Chinese.

[26] DV Miroshnichenko, NA Desna, YS Kaftan:Coke and Chemistry, Vol.58(2015), p.43

[27] M. Yu, J. Lin, C. Lu, et al: Journal of Henan Polytechnic university, Vol.28(2009), p.261 In Chinese

[28] Z. Xu, D. Cao: Coal Geology of China, Vol.24(2008), p.1 In Chinese

[29] G. Guo, L. Kong, Z. Wang, et al:Asian Journal of Chemisry. Vol.26(2014), p.1726

[30] L. Liu, M. Chu, T. Dang, et al: Journal of Fuel Chemistry and Technology, Vol.26(2014), p1726 In Chinese

[31] J. Zhao, in: Study on the Secondary Oxidation Spontaneous Combustion Miro-characteristics of Coal. Xi' an University of Science and Technology, (2015) In Chinese 